\title{
DIVULGAÇÃO DA RESPONSABILIDADE SOCIAL E DESEMPENHO DE UNIVERSIDADES BRASILEIRAS
}

\author{
DISCLOSURE OF SOCIAL RESPONSABILITY AND \\ PERFORMANCE OF BRAZILIAN UNIVERSITIES
}

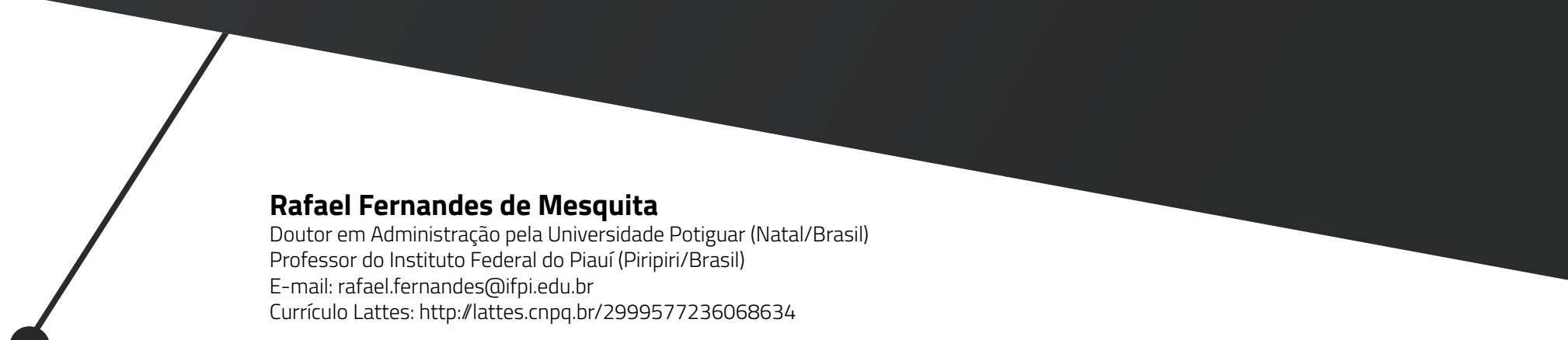

\section{Daniele Intravaia}

Master of Science, Finance and Investments, Copenhagen Business School (Copenhague/Dinamarca)

E-mail: danieleintravaia@gmail.com

\section{Johannes de Oliveira Lima Júnior}

Graduando em Administração pelo Instituto Federal de Educação, Ciência e Tecnologia do Piauí (Piripiri/Brasil)

E-mail: johannes.limajr@gmail.com

Currículo Lattes: http://lattes.cnpq.br/6029474431668790

\section{Jannielton de Sousa Santos}

Graduando em Administração pelo Instituto Federal de Educação, Ciência e Tecnologia do Piaúi (Piripiri/Brasil)

E-mail: jannieltonsantos500@gmail.com

Currículo Lattes: http://lattes.cnpq.br/0466503539353071

\section{Fátima Regina Ney Matos}

Doutora em administração pela Universidade Federal de Pernambuco (Recife/Brasil)

Professora no Instituto Superior Miguel Torga (Coimbra/Portugal)

E-mail: fneymatos@ismt.pt

Currículo Lattes: http://lattes.cnpq.br/5977512127210432

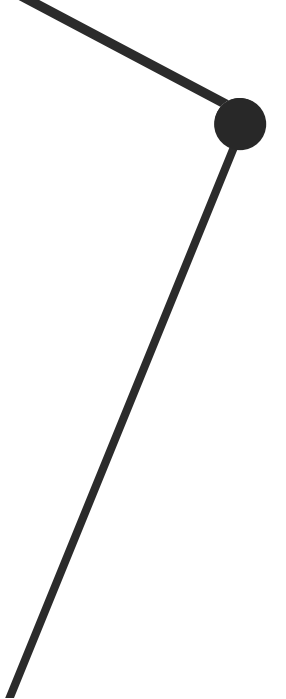

Recebido em: 12 de setembro de 2019 Aprovado em: 21 de novembro de 2019 Sistema de Avaliação: Double Blind Review RGD | v. 17 | n. 1 | p. 70-86 | jan./abr. 2020 DOI: https://doi.org/10.25112/rgd.v17i1.2022 


\section{RESUMO}

O contexto de debate da Responsabilidade Social (RS), apesar de bastante conhecido, apresenta vieses pouco abordados ou que emergem como suas ramificações, tal como a comunicação da RS. No que tange às universidades, a relação entre a divulgação das ações de responsabilidade social e o seu desempenho pode ainda não estar evidente. Desta forma, o problema de pesquisa que norteia este trabalho é: qual a relação entre a divulgação da responsabilidade social das universidades e o seu desempenho? Assim, objetivou-se analisar a relação entre o desempenho de universidades brasileiras e a divulgação da responsabilidade social em seus sítios eletrônicos. Para isso, foram selecionadas 17 universidades brasileiras presentes no World University Rankings 2015-2016 da Times Higher Education, e os dados foram coletados de seus websites utilizando os sete indicadores CSRIDOW, analisados a partir do coeficiente de correlação de Pearson. Como resultados, não houve significância na relação testada e não há suporte estatístico para apoiar a correlação entre o desempenho das universidades brasileiras e a divulgação de suas ações de responsabilidade social, corroborando estudos prévios.

Palavras-chave: Universidades. Responsabilidade Social. Comunicação. Desempenho.

\section{ABSTRACT}

The context of Social Responsibility (SR) debate, although well known, presents biases that are little addressed or emerge as its ramifications, such as the disclosure of the SR. With regard to universities, the relationship between disclosure of social responsibility actions and their performance may not yet be evident. Thus, the research problem that guides this work is: what is the relationship between the disclosure of the social responsibility of universities and their performance? Thus, the objective was to analyze the relationship between the performance of Brazilian universities and the disclosure of social responsibility on their websites. For this, 17 Brazilian universities were selected from the Times Higher Education World University Rankings 2015-2016, and data were collected from their websites using the seven CSRIDOW indicators, analyzed from Pearson's correlation coefficient. As a result, there was no significance in the relationship tested and there is no statistical support to support the correlation between the performance of Brazilian universities and the disclosure of their social responsibility actions, corroborating previous studies.

Keywords: Universities. Social responsibility. Communication. Performance. 


\section{INTRODUÇÃO}

O contexto de debate da Responsabilidade Social (RS) nas organizações é embasado por diversas abordagens teóricas (GARRIGÁ; MELÉ, 2004) e, apesar de bastante conhecidas, há vieses pouco abordados ou que emergem como suas ramificações, tal como a comunicação da responsabilidade social (WANDERLEY et al., 2008; SOUSA FILHO et al., 2010, SOUSA FILHO et al., 2014). Morsing e Schultz (2006) informam que as mensagens sobre ações de RS frequentemente evocam reações positivas e fortes no grupo de stakeholders da organização, apesar da divulgação da RS pelas empresas também atrair olhares críticos (VALLENTIN, 2001). Os resultados destas ações de divulgação, geralmente, são refletidos na imagem da organização e em sua reputação, o que implica em um número cada vez maior de empresas que adotam esta prática em busca de atenção (SOUSA FILHO; WANDERLEY, 2007).

Os holofotes globais sobre a temática e a evidente necessidade de estender os papéis públicos de instituições de ensino trouxeram as discussões sobre RS ao âmbito das universidades como objeto de estudo (VOLPI, 1996). Rico (2004) trata dos enfrentamentos de questões sociais e como a parceria entre instituições privadas e o Estado podem auxiliar nestes méritos, possibilitando a compreensão de que o ensino pode ser um dos meios desta contribuição. Franco (2014) afirma que a RS não abrange exclusivamente organizações empresariais, mas se estende às igrejas, hospitais, governo, universidades e outras organizações, assim como se estendem seus objetivos e suas formas de atuação frente aos stakeholders. Santos, Oliveira e Rodrigues (2015) corroboram esta ideia enquanto afirmam que é um dever do Estado atender as necessidades sociais e atuar na redução de danos ao meio ambiente, entre outras responsabilidades vinculadas ao social.

Desta forma, além de tornar-se um dever, o papel social como uma extensão das obrigações legais, a RS também adentra o campo universitário como um objetivo estratégico de diferencial competitivo, na busca por melhores resultados de desempenho frente os concorrentes. Sendo assim, a universidade deve ter a capacidade de gerar e difundir a ciência, bem como colocar em prática um conjunto de conhecimentos (científico, tecnológico, filosófico, artístico), no fito de contribuir com a própria comunidade universitária e também com a comunidade do seu entorno, sem perder de vista os desafios sociais, culturais, ambientais e econômicos (RIBEIRO; MAGALHÃES, 2018). Campo controverso na literatura especializada, a relação entre RS e desempenho ainda gera resultados conflituosos, ora informando ganhos positivos ou neutros, ora negativos. No que tange às universidades, esta relação pode ainda não estar evidente. Assim, emerge o seguinte problema de pesquisa que norteará este trabalho: qual a relação entre a divulgação da responsabilidade social das universidades e o seu desempenho? Para responder este questionamento, o objetivo do estudo é analisar a relação entre o desempenho de universidades brasileiras e a divulgação da responsabilidade social em seus sítios eletrônicos. 


\title{
2 REFERENCIAL TEÓRICO
}

\subsection{RESPONSABILIDADE SOCIAL UNIVERSITÁRIA}

As universidades possuem uma responsabilidade social intrínseca quanto à formação de futuros profissionais e líderes, causando impacto direto à sociedade e ao desenvolvimento econômico, social e político (NIEBLES-NÚÑEZ, et al., 2018). Como a RS é um campo amplo e de inúmeras facetas, é possivel que essa ideia seja aplicada tanto no meio empresarial e educacional. Deste modo, é usual que haja diferenças, como Ribeiro e Magalhães (2014) relatam:

\begin{abstract}
Embora o conceito de RSU preceda do campo empresarial com a responsabilidade corporativa, observa-se que no campo da educação superior a sua natureza adquire uma nova configuração, dado o caráter público da educação, para além de um produto ou serviço comumente comercializado. Tratando-se de universidade, a responsabilidade social configura-se no esforço desta em promover ações baseadas em princípios éticos que garantam o desenvolvimento nas suas múltiplas dimensões: social, cultural, ambiental e económica. Assim, a universidade deve convergir as suas ações subsidiadas em compromissos sociais e educacionais, tais como compromisso com equidade social, com sustentabilidade, com exercício da cidadania e da democracia, com a ciência e com a geração de conhecimento para o desenvolvimento e a melhoria da qualidade de vida das pessoas (RIBEIRO; MAGALHÃES, 2014, p. 151-152).
\end{abstract}

Essa diferença persiste mesmo considerando que a responsabilidade social corporativa abrange aspectos semelhantes à RSU como a sustentabilidade e a ética, dentro do seu meio de atuação (BOECHAT; BARRETO, 2018). Vasilescu et al. (2010), em seu artigo, pretendeu explicar a mudança da Responsabilidade Social Corporativa (RSC) para a Responsabilidade Social Universitária (RSU), apresentando o marco conceitual da Responsabilidade Social e da universidade como um tipo especial de organização que precisa adotar uma estratégia de responsabilidade social como as outras organizações, a fim de atender às expectativas das partes interessadas (presentes estudantes, futuros estudantes, apoiadores, etc). 0 artigo apresenta, por outro lado, o modelo de responsabilidade social da General University no contexto da globalização que se desenvolve no modelo real de responsabilidade Social Universitária e desafios do sistema de ensino superior romeno.

Nesta lógica, partindo de uma necessidade geral de padronização da avaliação da atuação de Instituições de Ensino Superior (IES), tornou-se necessário um sistema que permite ao Estado a verificação da atuação destas, tendo sua implementação, metodologia e relatórios padronizados (MARTíNOGUERA et al., 2018). No Brasil, esse sistema se deu com a instituição do Sistema Nacional de Avaliação 
da Educação Superior (SINAES), pela lei $n^{\circ}$ 10.861, de 14 de abril de 2004. A responsabilidade social, dentro do sistema educacional superior, foi incluída em uma das dez dimensões de avaliação das IES (BRASIL, 2014a), sendo regulamentada pela Portaria Nº 2.051 (BRASIL, 2014b). A partir disso, começouse a ser discutido a chamada Responsabilidade Social Universitária (RSU), que incorpora um conceito empresarial em âmbito educacional. No entanto, esses dispositivos legais não definiram claramente o que seria a responsabilidade social de uma IES até o momento - dilema notado pela literatura como a principal fragilidade da avaliação de universidades quanto à responsabilidade social (MARTí-NOGUERA, et al., 2018).

Para alguns autores, a educação per se representa uma forma de compromisso social praticada pelas IES (MORETTO; FIOREZE, 2018). Assim como demonstra o estudo de Rus et al. (2014), que investigaram a relação entre organização de aprendizagem e responsabilidade social universitária. Os autores avaliaram essa relação nos três grupos de partes interessadas internas: alunos, funcionários com liderança, funções de monitoramento, avaliação e controle, e equipe envolvidos no desenvolvimento dos programas de estudo. A pesquisa apontou diferentes dimensões da organização de aprendizagem e apresentaram vários graus de associação com a responsabilidade social da universidade, sendo que essas relações variaram de acordo com a associação formal organizacional. Contudo, o governo brasileiro, em seu instrumento de avaliação externo de 2014, estabeleceu uma definição de responsabilidade social da IES:

\begin{abstract}
A responsabilidade social refere-se às ações da instituição (com ou sem parceria) que contribuem para uma sociedade mais justa e sustentável. Nesse sentido, deverão ser verificados trabalhos, ações, atividades projetos e programas desenvolvidos com e para a comunidade, objetivando a inclusão social, o desenvolvimento econômico, a melhoria da qualidade de vida, da infraestrutura urbana/local e a inovação social (BRASIL, 2014, p. 35).
\end{abstract}

Dessa forma, a lacuna anteriormente citada é parcialmente fechada a partir do aporte de alguns indicadores, com as IES incumbidas da tarefa de formarem cidadãos com responsabilidade e ética, promovendo atividades de ensino, pesquisa, extensão e gestão, de maneira holística (NUNES et al., 2017). Nessa perspectiva, as universidades são percebidas como recurso transformador que promovem 0 cumprimento de ações éticas e transparentes, colaborando para o desenvolvimento sustentável (NIEBLESNÚÑEZ et al., 2018). Machado et al. (2013) evidenciam que 22 práticas sustentáveis são realizadas por grande parte das Universidades do país. Ademais, os autores constataram que as instituições que priorizam a questão ambiental, implantando um Sistema de Gestão Ambiental e departamento específico 
para sua gestão, apresentam nível mais elevado de adoção de práticas, sendo as principais motivações relacionadas com a preocupação em relação ao meio ambiente e em conscientizar a sociedade por meio de projetos de educação/servindo como exemplo.

Contudo, a definição de responsabilidade social de IES não salienta em nenhum momento a prática de extensão, de acordo com Martí-Noguera et al. (2018). Os autores apresentam esta ausência como uma falha, uma vez que essas ações sociais podem ser interpretadas como atribuições da extensão universitária (uma das dimensões das IES, quando se pensa no tripé universitário do ensino-pesquisa-extensão). Além disso, segundo Moretto e Fioreze (2018), apesar da regulamentação e exigência da responsabilidade social em IES, as universidades ainda carecem da discussão de quais cidadãos pretende-se formar e de qual sociedade deve ser construída.

Nesse sentido, a RSU desafia as IES a irem além de sua missão essencial, representando as universidades como organizações que devem contribuir para o desenvolvimento da sociedade (MARTíNOGUERA et al., 2018). Através do fomento da diversidade de conhecimento "próprio de um lócus reflexivo, crítico e inventivo, que garanta uma docência da educação superior com capacidade para formar sujeitos socialmente e politicamente comprometidos [...]" (NUNES et al., 2017, p. 12), as IES contribuem para a sociedade e formam cidadãos. Em adição, Alamilla et al. (2017) relatam que é proposto que se alcance um alto nível de cidadania, mas que esse objetivo é algo de muita complexidade para que seja alcançado dentro da universidade e para que isso ocorra isso deve ser implementado com o auxílio das ações de RSU que é considerada como um eixo prioritário do modelo educativo.

Mera e Espinosa (2018) relatam que o modelo de RSU deve ser orientado para que coexista no ambiente universitário uma cultura de paz, junto com as demais ações de RSU pois, para os participantes do estudo (cerca de 74\%), é importante que a universidade promova ações voltadas para criação de uma cultura de paz. Contudo, o modelo de RSU não aborda de forma de efetiva o ideal de educação para a paz. Ribeiro e Magalhães (2018) relatam os desafios de instauração das RSU nos ambientes acadêmicos das universidades e essas dificuldades estão relacionadas à criação dos compromissos da instituição, os meios para manter esses compromissos ativos, além dos recursos para serem utilizados nas ações de RSU, o que configura a alta complexidade desse processo.

Além disso, como mostra o estudo de Dagilienè e Mykolaitienè (2015), em que investigaram como as universidades públicas lituanas implementam o conceito de responsabilidade social e divulgam informações sustentáveis em seus relatórios anuais de desempenho, foi identificado que a notificação de responsabilidade social não é obrigatória e que as universidades estão se concentrando em áreas que parecem essenciais para eles. Há uma discussão maior acerca de áreas como Economia e áreas sociais, enquanto o meio ambiente e a educação não são refletidos em algumas universidades. No entanto, há 
falta de relatórios uniformes, portanto, as divulgações de diferentes universidades não são comparáveis, não ausência de uma escala que procure padronizar estas observações.

Em face ao exposto, verifica-se que os autores apontados neste tópico, buscaram expor suas pesquisas sobre RSU, mostrando que o assunto costuma gerar pesquisas com aspectos semelhantes, porém, com focos diferentes. As pesquisas de Dagilienè e Mykolaitienè, (2015), Rus et al. (2014), Ribeiro e Magalhães (2014), Machado et. al (2013) e Vasilescu et al. (2010) estão alinhadas com esse estudo, tendo em vista que os autores trataram sobre a falta de uniformidade das informações geradas pela universidade, e que o resultado positivo está associado com a formação da organização e a implantação de um departamento específico, e por fim, apresentam um modelo de responsabilidade social universitária.

\subsection{COMUNICAÇÃO DA RESPONSABILIDADE SOCIAL}

A responsabilidade social não se configura em algo exclusivo das IES ou do campo da educação, esse tema vem sendo mais debatido a partir de mudanças em sistemas econômicos e políticos (RIBEIRO; MAGALHÃES, 2014). Afirmando essa ideia, Fernandes et al. (2018), relatam que a RS dentro das empresas se relaciona com a perspectiva do tripé da sustentabilidade o que possibilita estabelecer uma relação entre sustentabilidade e responsabilidade social, com isso as organizações passaram a ter uma maior exigência para adotar ações de responsabilidade social.

Desse modo, a Responsabilidade Social, quando aplicada em organizações, se constitui na ideia de criação de valor, dentro do âmbito ao qual ela é aplicada, como também se relaciona com a imagem da empresa, que pode ser estimada como positiva pelo meio social a qual pertence (BOECHAT; BARRETO, 2018). Em complemento a isso, Baraibar-diez e Sotorrío (2018), relatam que as ações de responsabilidade social podem levar à criação de uma boa reputação e devem realizar esse processo de modo transparente e compreensivo para que, assim, aumente o índice de confiança da empresa como sua própria reputação.

A literatura sobre Responsabilidade Social Corporativa tem seu marco teórico inicial atribuído aos textos de Bowen (1953) e os amplamente citados nos trabalhos de Friedman (1962), Carrol (1979, 1999) e Freeman (1984). Desde então a literatura acadêmica das organizações tem se preocupado em estudar o fenômeno da RS. Ações de RS são importantes e tem como objetivo demonstrar o interesse social de uma instituição, como uma empresa ou uma universidade em serem aceitas pelo ambiente humano onde elas trabalham e operam. Portanto, a divulgação de tais atos é um habilitador fundamental de práticas de responsabilidade social (YAO et al. 2011).

A RS pode ser considerada um fator diferenciador em mercados competitivos, gerando vantagens frente aos competidores (ASHLEY, 2002), sendo pautada como uma forma de distribuir novamente para a sociedade, uma parte do valor criado pela empresa (BATISTA, 2018). Desta forma, divulgar ações 
de RS pode funcionar como uma ação em si na busca por melhores desempenhos (SOUSA FILHO; WANDERLEY, 2007). A relação entre desempenho e ações de RS pode ser verificada em diversos estudos, principalmente quando se trata do desempenho financeiro (BRAMMER; MILLINGTON, 2008; SURROCA; TRIBO; WADDOCK, 2010; ANDERSEN; DEJOY, 2011). Mas há pouco ou quase nenhum consenso nestes méritos, pois há diversos estudos que encontram resultados conflituosos (WOOD, 2010), dificultando a legitimação da afirmação desta relação.

Neste sentido, a comunicação das ações de RS praticadas pelas empresas tem sido uma ferramenta que possibilita ganhos em imagem e reputação, uma forma subjetiva de trazer retorno aos investimentos realizados nestas ações (MESQUITA et al., 2015). A internet tem sido o meio mais utilizado para realizar essa comunicação, principalmente com os websites corporativos, funcionando como instrumentos de relações públicas (CAPRIOTTI; MORENO, 2007). A popularização da internet, bem como as facilidades de uso deste meio na comunicação da RS recebeu atenção de pesquisas (WANG; CHAUDHRI, 2009; GOMEZ; CHALMETA, 2011; KIM; NAM, 2012) que informaram sobre a relação custo-benefício e facilidade de controle da informação, o processo interativo que se estabelece e a possibilidade de destinar informações aos mais diversos stakeholders da organização. Autores como Batista (2018), defendem a utilização de relatórios integrados, isto é, a combinação de um relatório financeiro com a divulgação de informações não-financeiras, assim, apresentando de uma melhor forma o processo de criação de valor para os stakeholders.

Para analisar como as empresas se posicionam em sua abordagem de comunicação da RS, vários trabalhos já utilizaram o Indicador de Comunicação da Responsabilidade Social (CSRIDOW) desenvolvido por Wanderley et al. (2008) a partir de uma proposta inicial de Sousa Filho e Wanderley (2007). O CSRIDOW possui sete indicadores: (a) menção de responsabilidade social empresarial (RSE) ou algo equivalente na página inicial (homepage) da organização; (b) código de conduta disponível; (c) comunicação de projetos corporativos em RSE; (d) respectivos parceiros; (e) resultados; (f) relatório de RSE ou sustentabilidade disponível no website; e (g) menção sobre RSE na missão e/ou valores da organização. Este conjunto de indicadores foi utilizado para atender ao teste da seguinte hipótese:

H1 - Há correlação entre a comunicação de informaç̧̃̃es de responsabilidade social e o desempenho das universidades. 


\section{Gestãoe \\ Desenvolvimento}

e-ISSN: 2446-6875

p-ISSN: $1807-5436$

\section{ASPECTOS METODOLÓGICOS}

Com a finalidade de responder ao questionamento da pesquisa: "qual a relação entre a divulgação da responsabilidade social das universidades e o seu desempenho?" este trabalho de pesquisa utilizou dados coletados a partir de análise de conteúdo - com codificação e numeração de conteúdo (BARDIN, 2011) disponível em sítios eletrônicos de instituições de ensino superior brasileiras bem posicionadas no ranking de melhores universidades (World University Rankings 2015-2016) da Times Higher Education. Os dados primários foram coletados a partir da observação de websites de universidades brasileiras no ranking das 800 melhores instituições para os anos 2015-2016 divulgado pela Times Higher Education, durante o mês de dezembro do ano de 2015 e tabulados no software de análises estatísticas SPSS.

O ranking da Times Higher Educationfoi escolhido por ser uma classificação estável (USHER, 2015) que posiciona boas universidades de todo o globo por seu desempenho em ensino, pesquisa, transferência de conhecimento e perspectiva internacional. No resultado da avaliação 2015-2016 deste ranking dezessete universidades brasileiras fazem parte de uma lista que cita 800 instituições de ensino superior mundiais. As universidades listadas no ranking estão expostas na Tabela 1, com seus nomes seguidos pela sua posição no ranking.

Tabela 1 - Universidades listadas no Ranking

\begin{tabular}{ll}
\hline Universidade de São Paulo (USP) & 251-300 \\
Universidade Estadual de Campinas (Unicamp) & $351-400$ \\
Universidade Federal do Rio de Janeiro (UFRJ) & $501-600$ \\
Pontifícia Universidade Católica do Rio de Janeiro (PUC-Rio) & $501-600$ \\
Universidade de Brasília (UnB) & $601-800$ \\
Universidade Federal da Bahia (UFBA) & $601-800$ \\
Universidade Federal de Minas Gerais (UFMG) & $601-800$ \\
Universidade Federal do Paraná (UFPR) & $601-800$ \\
Universidade Federal do Rio Grande do Sul (UFRGS) & $601-800$ \\
Universidade Federal de Santa Catarina (UFSC) & $601-800$ \\
Universidade Federal de São Carlos (UFSCar) & $601-800$ \\
Universidade Federal de Viçosa (UFV) & $601-800$ \\
Universidade Federal de Lavras (UFLA) & $601-800$ \\
Pontifícia Universidade Católica do Paraná (PUCPR) & $601-800$ \\
Pontifícia Universidade Católica do Rio Grande do Sul (PUCRS) & $601-800$ \\
Universidade do Estado do Rio de Janeiro (UERJ) & $601-800$ \\
Universidade Estadual Paulista (Unesp) & $601-800$ \\
\hline
\end{tabular}

Fonte: Elaborado a partir de dados do Ranking “World University Rankings 2015-2016". 


\section{Gestãoe \\ Desenvolvimento}

e-ISSN: 2446-6875

p-ISSN: 1807-5436

Logo após identificação das instituições, seguiu-se com a coleta de dados em seus sítios eletrônicos. Para este fim foram utilizados os sete indicadores CSRIDOW, com resposta binária em cada um deles: (1) para confirmar a verificação do indicador; e (0) para confirmar a não verificação do indicador. Após aponte destas informações, foi calculado um índice geral a partir da soma dos sete indicadores, este índice e a posição da universidade no ranking foram utilizados como variáveis na análise de correlação.

A correlação momento-produto destaca a intensidade de associação entre duas variáveis métricas, utilizando o coeficiente de correlação de Pearson (MALHOTRA, 2012). Para uma amostra com " $n$ " observações e duas variáveis, dadas por " $x$ " e " $y$ " o cálculo deste coeficiente pode ser expresso na seguinte equação:

$$
\rho=\frac{\sum_{i=1}^{n}\left(x_{i}-\bar{x}\right)\left(y_{i}-\bar{y}\right)}{\sqrt{\sum_{i=1}^{n}\left(x_{i}-\bar{x}\right)^{2}} \cdot \sqrt{\sum_{i=1}^{n}\left(y_{i}-\bar{y}\right)^{2}}}=\frac{\operatorname{cov}(X, Y)}{\sqrt{\operatorname{var}(X) \cdot \operatorname{var}(Y)}}
$$

O valor de varia entre -1,0 e 1,0 e pode ser interpretado como forte, fraco ou inexistente. 0 sinal indica a direção positiva ou negativa do relacionamento e os valores sugerem a força da relação entre as variáveis. As correlações podem ser classificadas conforme segue: i) relação forte, com $=[ \pm 0.7$; \pm 1$]$; ii) relação de força moderada, com = $[ \pm 0.6 ; \pm 0.69$ ]; e iii) relação fraca, com = $[< \pm 0.6]$. (CHOUDHURY, 2009). Os dados foram analisados após coletados e os resultados desta análise podem ser verificados na seção seguinte.

\section{ANÁLISE E DISCUSSÃO DOS RESULTADOS}

Para testar a hipótese que trata da correlação entre a comunicação de responsabilidade social (CSRIDOW) e o desempenho de universidades brasileiras no ranking da Times Higher Education, foi feita a análise de correlação de Pearson, cujos resultados estão visiveis na Tabela 2 logo a seguir.

\begin{tabular}{|c|c|c|}
\hline & & Ranking \\
\hline CSRIDOW & $\begin{array}{l}\text { Coeficiente de correlação } \\
\text { Sig. (2-tailed) } \\
\text { N }\end{array}$ & $\begin{array}{l}0,205 \\
0,430 \\
17\end{array}$ \\
\hline
\end{tabular}


Conforme observado na Tabela 2, não houve significância na relação testada e, assim, a hipótese do estudo foi rejeitada. Deste modo, não há suporte estatístico para apoiar a correlação entre o desempenho das universidades brasileiras e seu posicionamento no ranking utilizado. Resultados similares foram encontrados, mesmo que tomando por base a relação entre desempenho financeiro e comunicação de RS em grandes empresas privadas, no estudo de Sousa Filho et al. (2014) e no trabalho de Lucian et al., (2007).

A pesquisa de Sousa Filho et al. (2014), assim como esta, utiliza o CSRIDOW com o intuito de analisar a comunicação da RSE em 124 grandes empresas localizadas em 12 países emergentes. Com isso, os resultados apresentam que, apesar do crescimento da comunicação da RSE, não houve correlação entre a divulgação de RSE e o desempenho financeiro nessas organizações. Em adição, Lucian et al. (2007) investigou a relação entre o desempenho financeiro e a comunicação da responsabilidade social em 148 corporações presentes em 12 países membros do G-20. De acordo com os autores, das empresas estudadas, as que obtiveram o melhor desempenho financeiro foram as que menos comunicaram suas práticas de RSE, ou seja, assim como neste estudo, Lucian et al., (2007), bem como Sousa Filho et al. (2014) não encontraram correlação entre desempenho da empresa e comunicação da Responsabilidade social mesmo em empresas privadas. Desse modo, as universidades seguiram essa mesma tendência, assim como se confirmou nos resultados desta pesquisa.

A dinâmica de criação da RS, dentro das universidades, é de alta complexidade, pois as IES necessitam criar compromissos, manter os compromissos ativos, além de definir os recursos para que esse processo ocorra (RIBEIRO; MAGALHÃES, 2018). Em comparação ao estudo de Sousa Filho et al.(2010), é possivel perceber que as empresas que foram estudadas possuem um plano de RS bem definido com as metas e com ações que englobam a sociedade onde são amplamente divulgadas no website, os códigos de ética e conduta das empresas, os projetos sociais, os resultados dos projetos, as parcerias e relatórios. Assim visando manter os valores comuns tanto à responsabilidade social universitária e responsabilidade social corporativa, como a sustentabilidade e ética (BOECHAT; BARRETO, 2018).

Apesar da RS ser uma dimensão cobrada obrigatoriamente na avaliação das IES (MARTÍ-NOGUERA, et al., 2018), sua comunicação não é obrigatória, portanto, assim como apontado no referencial por Dagilienè e Mykolaitienè (2015), as IES preferem enfatizar áreas mais essenciais, tais como Economia e áreas sociais. Outra possível razão para a baixa correlação entre comunicação de RS e desempenho das universidades é explicada por Moretto e Fioreze (2018, p. 14), em que as universidades ainda carecem de maiores reflexões sobre a responsabilidade social, perpetuando a reprodução de "uma concepção 
utilitarista historicamente arraigada" de que as universidades já são, em sua essência, socialmente responsáveis. Essa concepção, ainda existente, inibe a criação de práticas de RS no âmbito universitário, consequentemente, a divulgação dessas práticas tem sua relevância reduzida.

Os achados possibilitam a compreensão da pouca divulgação de ações de RS no âmbito dos websites das universidades brasileiras elencadas no estudo. Isto implica na interpretação de que este tipo de organização ainda não esteja adotando estratégias competitivas como outras que já usam a internet para este tipo de comunicação, principalmente por meio da web (WANG; CHAUDHRI, 2009; GOMEZ; CHALMETA, 2011; KIM; NAM, 2012).

\section{CONCLUSÃo}

O presente estudo analisou a comunicação da RS de universidades brasileiras participantes do Ranking "World University Rankings 2015-2016" da Times Higher Education com a finalidade de responder ao seguinte questionamento: "qual a relação entre a divulgação da responsabilidade social das universidades e o seu desempenho"? A atenção a este objetivo possibilitou a conclusão de que não há correlação significante entre o desempenho destas universidades e a divulgação de suas ações de RS. Este resultado é derivado do baixo valor calculado para o índice utilizado no estudo, demonstrando pouca atenção destas instituições na comunicação da sua responsabilidade social.

Resultados similares foram encontrados em outros estudos, mesmo se tratando de empresas privadas e a divulgação da RSC. No entanto, no que concerne às universidades, a adoção de práticas de responsabilidade social, e sua consequente notificação, caminha em passos lentos, visto que, o gap presente entre a definição de responsabilidade social em IES, estabelecida pela legislação, e as atuais ações sociais praticadas pelas universidades, ainda está parcialmente aberto. Além disso, a noção préexistente de que a educação, per se, já é algo socialmente responsável, afeta a expansão e/ou adoção de estratégias relacionadas a este tema.

Levando isso em consideração é perceptível que as empresas privadas têm maior estrutura técnica, que possibilita a esse tipo de organização, executarem os planos de RS com um maior aproveitamento, e assim, conseguir manter as ações de RS ao longo do tempo, se beneficiando e beneficiando a sociedade do seu entorno, mesmo que a divulgação dessas ações não implique em seu desempenho. 


\section{Gestãoe \\ Desenvolvimento}

e-ISSN: 2446-6875

p-ISSN: $1807-5436$

\section{REFERÊNCIAS}

ALAMILLA, N. M. E. et al. Ciudadanía: análisis de algunos elementos del Modelo de Responsabilidad Social Universitaria en una universidad pública. Revista CS, p. 77-104, 2017.

ANDERSEN, M. L.; DEJOY, J. S. Corporate social and financial performance: The role of size, industry, risk, R\&D and advertising expenses as control variables. Business and Society Review, v. 116, n. 2, p. 237256, 2011.

ASHLEY, P. A. Ética e responsabilidade social nos negócios. São Paulo: Saraiva, 2002.

BARAIBAR-DIEZ, E.; SOTORRÍO, L. L. O efeito mediador da transparência na relação entre responsabilidade social corporativa e reputação corporativa. Revista Brasileira de Gestão de Negócios-RBGN, v. 20, n. 1, p. 05-21, 2018.

BARDIN, L. Análise de conteúdo. São Paulo: Edições 70, 2011.

BATISTA, N. Integrated reporting stimulates strategic communication of corporate social responsibility? A marketing perspective analysis based on Maignan, Ferrell and Ferrell's stakeholder model of corporate social responsibility in marketing. Media \& Jornalismo, v. 18, n. 33, p. 43-60, 2018.

BOECHAT, A. C.; BARRETO, A. M. Uma reflexão conceptual sobre a Responsabilidade Social Corporativa e a sua relação com a Comunicação Estratégica. Media \& Jornalismo, v. 18, n. 33, p. 25-41, 2018.

BOWEN, H. R. Social responsibilities of the businessman. Harper \& Row: New York, 1953.

BRAMMER, S.; MILLINGTON, A. Does it pay to be different? An analysis of the relationship between corporate social and financial performance. Strategic Management Journal, v. 29, n. 12, p. 1325-1343, 2008.

BRASIL. Lei n. ${ }^{\circ}$ 10.861, de 14 de abril de 2004. Institui o Sistema Nacional de Avaliação da Educação Superior-SINAES e dá outras providências. Diário Oficial da União, n. 72, 2004a.

BRASIL. MINISTÉRIO DA EDUCAÇÃO. Instrumento de Avaliação Institucional Externa. Subsidia os atos de credenciamento, recredenciamento e transformação da organização acadêmica (presencial). 2014.

BRASIL. Portaria n. 2.051, de 9 de julho de 2004: Regulamenta os procedimentos de avaliação do Sistema Nacional de Avaliação da Educação Superior (SINAES), instituído na Lei nº. 10.861, de 14 de abril de 2004b. 


\section{Gestãoe \\ Desenvolvimento}

e-ISSN: 2446-6875

p-ISSN: $1807-5436$

CAPRIOTTI, P.; MORENO, A. Corporate citizenship and public relations: The importance and interactivity of social responsibility issues on corporate websites. Public relations review, v. 33, n. 1, p. 84-91, 2007.

CARROL, A. B. A three-dimensional conceptual model of corporate performance. Academy of Management Review, v. 4, p. 17-25, 1979.

CARROL, A. B. Corporate social responsibility: evolution of a definitional construct. Business \& Society, v. 38, n. 3, p. 268-295, 1999.

CHOUDHURY, A. Statistical Correlation. 2009. Disponivel em: http://explorable.com/statistical-correlation Acesso em: 20 dez. 2015.

DAGILIENĖ, L.; MYKOLAITIENĖ, V. Disclosure of social responsibility in annual performance reports of universities. Procedia-Social and Behavioral Sciences, v. 213, p. 586-592, 2015.

DANI, A. C.; PICOLO, J. D.; KLANN, R. C. Gender influence, social responsibility and governance in performance. RAUSP Management Journal, v. 54, n. 2, p. 154-177, 2019.

DEBELJAK, J.; KRKAC, K.; BUŠLJETA BANKS, I. Acquiring CSR practices: from deception to authenticity. Social responsibility journal, v. 7, n. 1, p. 5-22, 2011.

FERNANDES, A. R. J.; FONSECA, S. E.; CUNHA, C. L. Responsabilidade Social e Influências sobre Retornos de Cotações: Um Estudo Acerca do Desempenho de Índices de Sustentabilidade. Revista Administração em Diálogo-RAD, v. 20, n. 1, p. 25-39, 2018.

FRANCO, H. F. A Divulgação da Responsabilidade Social e Empresarial nos bancos Angolanos e Portugueses. 2015. Disponível em: http://comum.rcaap.pt/handle/10400.26/8198 Acesso em: 20 dez 2015.

FREEMAN, R. E. Strategic management: a stakeholder approach. Pitman: Boston, 1984.

FRIEDMAN, M. Capitalism and freedom. University of Chicago: Chicago, 1962.

GARRIGA, E.; MELÉ, D. Corporate social responsibility theories: mapping the territory. Journal of Business Ethics, v. 53, p. 51-71, 2004.

GOMEZ, L. M.; CHALMETA, R. Corporate responsibility in US corporate websites: A pilot study. Public relations review, v. 37, n. 1, p. 93-95, 2011.

JANKALOVA, M. Approaches to the evaluation of Corporate Social Responsibility. Procedia Economics and Finance, v. 39, p. 580-587, 2016. 


\section{Gestãoe \\ Desenvolvimento}

e-ISSN: 2446-6875

p-ISSN: 1807-5436

KIM, D.; NAM, Y. Corporate relations with environmental organizations represented by hyperlinks on the Fortune global 500 companies' websites. Journal of business ethics, v. 105, n. 4, p. 475-487, 2012.

LUCIAN, R.; WANDERLEY, L. S. O.; FARACHE, F.; SOUSA FILHO, J. M. Comunicação da responsabilidade social em websites e desempenho financeiro nas corporações do G-20. Anais do XXVII ENEGEP, Foz do Iguaçú, Brazil, 2007.

MACHADO, R. E.; FRACASSO, E. M.; TOMETICH, P.; NASCIMENTO, L. F. Práticas de gestão ambiental em universidades brasileiras. Revista de Gestão Social e Ambiental, v. 7, n. 3, p. 37, 2013.

MARTÍ-NOGUERA, J.; et al. La responsabilidad social universitaria en Iberoamérica: análisis de las legislaciones de Brasil, España y Perú. Revista iberoamericana de educación superior, v. 9, n. 24, p. 107-124, 2018

MARTINS, T. B.; CAVALCANTE, R. F. L.; SOUSA-FILHO, J. M. Comunicação da responsabilidade social na internet: uma abordagem voltada para o público interno. Revista Eletrônica de Ciência Administrativa, v. 13, n. 2, p. 219-232, 2014.

MERA, B. R. M.; ESPINOSA, K. V. B. Educar para la Paz: Una dimensión de La responsabilidad Social Universitária. Ciências Administrativas, v. 6, 2018.

MESQUITA, R. F.; PONTE, A. V.; RECHENE, S. T.; SOUSA FILHO, J. M.; MATOS, F. R. N. Responsabilidade Social Corporativa e Imagem/reputação: O Que Se Diz e Quem Fala Sobre Esta Relação? XVIII SEMEAD, 2015. Anais... Disponivel em: http://sistema.semead.com.br/18semead/resultado/trabalhosPDF/552. pdf Acesso em: 20 dez 2015.

MORETTO, C. M.; FIOREZE, C. Responsabilidade social e perspectiva democrática: refletindo a partir do enquadramento teórico do desenvolvimento humano. Avaliação: Revista da Avaliação da Educação Superior, v. 24, n. 1, 2018.

MORSING, M.; SCHULTZ, M. Corporate social responsibility communication: stakeholder information, response and involvement strategies. Business Ethics: A European Review, v. 16, n. 4, p. 323-338, 2006.

NIEBLES-NÚÑEZ, W.; et al. RESPONSABILIDAD SOCIAL: ELEMENTO DE FORMACIÓN EN ESTUDIANTES UNIVERSITARIOS. Revista Latinoamericana de Estudios Educativos (Colombia), v. 14, n. 1, p. 95-108, 2018

NUNES, E. B. L. L. P.; PEREIRA, I. C. A.; PINHO, M. J. A responsabilidade social universitária e a avaliação institucional: reflexões iniciais. Avaliação: Revista da Avaliação da Educação Superior (Campinas), v. 22, n. 1, p. 165-177, 2017. 


\section{Gestãoe \\ Desenvolvimento}

e-ISSN: 2446-6875

p-ISSN: $1807-5436$

RIBEIRO, R. C; MAGALHÃES, A. M. Política de responsabilidade social na universidade: conceitos e desafios. Educação, Sociedade \& Culturas, $n^{\circ}$ 42, 2014, 133-156.

RICO, E. M. A responsabilidade social empresarial e o Estado: uma aliança para o desenvolvimento sustentável. São Paulo Perspec., São Paulo, v. 18, n. 4, p. 73-82, Dec. 2004.

RUS, C. L.; CHIRICĂ, S.; RAȚIU, L.; BĂBAN, A. Learning organization and social responsibility in Romanian higher education institutions. Procedia-Social and Behavioral Sciences, v. 142, p. 146-153, 2014.

SANTOS, T. P. M.; OLIVEIRA, E. A. A. Q.; RODRIGUES, M. S. RESPONSABILIDADE SOCIAL E PLANO DIRETOR: um estudo da relação entre práticas e diretrizes. Latin American Journal of Business Management, v. 5, n. 2, 2015.

SOUSA FILHO, J. M. et al. Comunicação da Responsabilidade Social Empresarial em Websites Corporativos: Estudo Comparado com Grandes Empresas de Países Emergentes. Revista de Gestão Ambiental e Sustentabilidade: GeAS, v. 3, n. 3, p. 122-134, 2014.

SOUSA FILHO, J. M.; WANDERLEY, L. S. O. Divulgação da responsabilidade social empresarial: como os websites empresariais vêm sendo utilizados por empresas de varejo e energia. Cadernos EBAPE.BR $(\mathrm{FGV})$, v. 5, p. 1-13, 2007

SOUSA-FILHO, J. M., WANDERLEY, L. S. O. \& FARACHE, F. Websites corporativos na comunicação de responsabilidade social em distribuidoras de energia: um estudo longitudinal. Pretexto, v. 11, 72-89, 2010.

USHER, Alex. The Times Higher Education Rankings and the Mysterious "Rise of Asia". International Higher Education, n. 79, p. 15-16, 2015.

VALLENTIN, Steen. Pensionsinvesteringer, etik og offentlighed: ensystemteoretiskanalyseaf offentlig meningsdannelse. 2002. Tese de Doutorado. Copenhagen Business School Copenhagen Business School, Institut for Ledelse, Politikog Filosofi Department of Management, Politics and Philosophy.

VASILESCU, R.; BARNA, C.; EPURE, M.; BAICU, C. Developing university social responsibility: A model for the challenges of the new civil society. Procedia-Social and Behavioral Sciences, v. 2, n. 2, p. 4177 $4182,2010$.

VOLPI, M. T. A universidade e sua responsabilidade social. Porto Alegre: EDIPUCRS, 1996.

WANDERLEY, L. S. O., LUCIAN, R., FARACHE, F. \& SOUSA FILHO, J. M. CSR information disclosure on the web: a context-based approach analyzing the influence of country of origin and industry sector, Journal of Business Ethics, v. 82, p. 369-378, 2008. 


\section{Gestãoe \\ Desenvolvimento}

e-ISSN: 2446-6875

p-ISSN: 1807-5436

WANG, J.; CHAUDHRI, V. Corporate social responsibility engagement and communication by Chinese companies. Public Relations Review, v. 35, n. 3, p. 247-250, 2009.

WOOD, D. J. Measuring corporate social performance: a review. International Journal of Management Reviews, v. 12, n. 1, p. 50-84, 2010.

YAO, S.; WANG, J.; SONG, L. Determinants of social responsibility disclosure by Chinese firms. The Universityof Nottingham-China Policylnstitute. Discussion Paper, v. 72, 2011. 